\title{
The Path to Becoming a Resident Assistant at a Japanese University
}

\author{
Graham G. Robson ${ }^{1}$ \\ ${ }^{1}$ International Tourism Department, Toyo University, Tokyo, Japan \\ Correspondence: Graham Robson, International Tourism Department, Toyo University, Hakusan 5-28-20, \\ Bunkyo Ward, Tokyo, Japan, 112-8606. Tel: 81-(0)3-3945-8264. E-mail: robson@toyo.jp
}

Received: May 17, 2016

doi:10.5539/ies.v9n12p23
Accepted: July 6, $2016 \quad$ Online Published: November 24, 2016

URL: http://dx.doi.org/10.5539/ies.v9n12p23

\begin{abstract}
Resident Assistants (RAs) are a mainstay of many universities worldwide that offer accommodation to visiting students. They look after both the administrative side and, more importantly, the emotional side of ensuring visiting students, including students from other countries, fit primarily into the university accommodation, and also the host culture as a whole. With an increase in the number of foreign students coming to Japan, it has become necessary at hosting universities to employ RAs at university-provided accommodation for non-Japanese students. This qualitative study used interview data from three RAs employed at a university in Tokyo and inductively produced six sub-headings of data. The aim of the study is to find out motivations for becoming an RA and participants' perceptions prior to and during their jobs as RAs.
\end{abstract}

Keywords: resident assistant, qualitative research, Japanese university

\section{Introduction}

Many universities in Japan offer a range of study abroad experiences for their students. These programs range from short programs up to one month in length to programs for the full academic year. Programs like these help develop learners' language skills and intercultural understanding outside of Japan because opportunities for interaction with other cultures inside Japan are somewhat limited.

Although increasing students' language skills and cultural awareness during those months away from Japan is essential, what students do with that knowledge upon returning to Japan is an equally important issue to deal with. More often than not a student's study abroad experience is consigned similar to that of a mere a vacation. Upon returning to Japan, students may struggle to adjust to life back in Japan (Jones, 1997; Kidder, 1992). Oftentimes their continuation of foreign language development takes a backseat as Japanese university returnees from study abroad deal with reassessing their identities, and trying to plan the next step of their lives.

It is necessary to counter the problems of both skills gained while studying abroad becoming redundant upon returning to Japan and discomfort for reentry into Japanese life. To this end, one Japanese university has started to employ Japanese study abroad returnees to act as semi-permanent resident assistants at that university's accommodation for overseas students who visit Japan. It was hoped that Japanese resident assistants could provide help for overseas students to adjust to life in Japan through skills that had been developed in the multicultural settings they experienced in their study abroad locations. This would lead, it was hoped, to returning Japanese students playing a productive role for themselves and others after returning to Japan.

This study will analyze the first three study abroad returnees employed at a Japanese university as they come towards the end of their roles as resident assistants. This short paper uses resident assistants' perspectives to report on how their past experiences shaped this first cohort and what can be learned from their roles to benefit the university.

\section{The Role of Resident Assistants}

Much more common in American universities than Asian universities, resident assistants are usually students above the sophomore year who serve as live-in employees. According to Harmon (2011), the RA position encompasses five roles that include role model, counselor and teacher to the students they reside with. Harmon further explains typical RA duties are those such as providing resident students with help, steering students to resources, explaining and enforcing university rules and maintaining a safe environment for residents. Roussel and Elleven (2009) comment that RAs will possess certain characteristics that the university feels to be 
important. For this reason, they claim, the resident assistants will need a highly visible position in the halls of residence, with resident students hopefully looking up to them as role models. It is very important for the RAs to maintain this elevated and visible position in order to elicit confidence among the resident students.

It is not surprising that due to the range and number of students that attend universities, RAs will often have to deal with a diverse number of issues in the residences they work in (Blimling, 1998). With the expansion of overseas study, RAs will also need to deal with student visitors from different ethnic, cultural and religious backgrounds as part of their work. Indeed, in Japan the number of students registered as studying abroad in 2014 was up by $10 \%$ on the previous year, with a large increase among students from America, according to the Japanese government (MEXT, 2015). This makes the work of the RA incredibly challenging. Not only is there the problem of helping students adjust to a new way of life, but that could often mean providing that care to people who are not L1 speakers of the language.

\section{Rationale for this Study}

Research that focuses on resident assistants has been conducted mainly in the US. That research has focused on the qualities that RAs have (Shelton \& Mathis, 1976), as well as what motivates RAs to do their jobs (Bierman \& Carpenter, 1994; Denzine \& Andersen, 1999). Further research looks at what the job and training for the job entails (Aamodt, Keller, Crawford, \& Wilson, 1981; Bowman \& Bowman, 1995). There is also research that looks at the societal implications of RAs and minority groups (D'Augelli, 1989; Evans \& Broido, 1999). These studies focus on on-campus resident assistants and their student populations. In other research fields, how students adapt to the host culture during sojourns aboard from the perspective of the students themselves has been investigated (see Freed, 1998). However, very few studies exist that address how resident assistants interact with study abroad students. This is despite the proliferation of both resident assistants and research into study abroad. This study will address the lack of research into RAs who deal specifically with study abroad students in the Japan setting.

\section{Methods}

This section describes the setting, participants and the procedure.

\subsection{Setting}

The site used for this research is a medium-sized private liberal arts university (pseudonymously referred to as Kanto University). The university consists of 11 different faculties and is active in promoting study abroad opportunities for its Japanese students as well as establishing courses for study abroad students coming into Japan. The international students at Kanto University stay in a dormitory solely for their use. Each year Kanto University accepts around 30-40 international students mainly from the US and Europe onto its courses lasting for up to one academic year.

\subsection{Participants}

The first cohort of RAs to be employed at Kanto University all started in August 2015 with two finishing their job due to graduation and one continuing on into his final year at Kanto University at the time of reporting. All participants had been studying abroad in the previous semester for one academic year. The breakdown of the participants is shown below in Table 1. All the participants were Japanese nationals and enrolled in regular classes at Kanto University upon their return to Japan. Two of the RAs were finishing their job as RAs due to graduating university and one was planning to continue the RA job into his fourth year of university study.

Table 1. Participants in the Study

\begin{tabular}{ccccc}
\hline & Gender & Year & Place of study abroad & Status as RA \\
\hline RA1 & M & 3 & America & continuing \\
RA2 & F & 4 & Germany & finishing \\
RA3 & M & 4 & Holland & finishing \\
\hline
\end{tabular}

\subsection{Procedure}

The data in this study was collected using qualitative techniques to produce insights of a deeper nature. Data was collected over the course of five interviews with each participant, which lasted for about 30 minutes each and took place over a two-month period during their roles as RAs. Full consent was given from each participant to 
use data for research purposes. Previous data from the RA interviews served as the basis for loose follow-up questions for the following interviews. Question formats were based on guidelines set out by Spradley (1979, pp. 78-91), who advocates using a variety of different questions, including grand tour questions, example and experiential questions. Grand tour questions require a generalized answer. They include questions like, "Can you describe a typical day as an RA?" or "What kind of communication issues were you most concerned with during your time abroad?" Example questions can prompt informants to expand their ideas, and one such question was "Can you give me an example of how you felt your attitude had changed since being back in Japan?" Experiential questions were used to seek out more unusual answers, and one example was "Can you tell me experiences you had that helped you to become more motivated to improve your communication skills?" The use of example and experience questions helped to obtain specific details from the grand tour questions. Lastly, the data was coded (Miles \& Huberman, 1994) by inductively generating recurring themes from the data. The author read through the data many times until salient themes began to emerge.

\section{Results}

For this paper, six codes have been employed to categorize the RAs responses. In this section, these codes appear in rough chronological order starting from motivation to study abroad, moving into reasons for applying to be an RA and, lastly, related to the job of RA itself.

\subsection{Reasons for Study Abroad}

In order to better understand the motivations for becoming RAs, it is important to look back at their attitudes associated with studying abroad in the first place. It seems that some RAs chose to have study abroad experiences where they would have less chance of meeting other Japanese students. RA3 claimed that he had researched the study abroad population breakdown of the potential universities he planned to visit. He narrowed down his search to places where Asian students made up around 1\% of the student body. He based his final decision on the university after visiting a study abroad fair; an exposition where universities advertise their programs to prospective students. After meeting one student who had come back from a study period at the university he was applying for, RA3 judged that student's English to be quite poor. This was compared to other students he had met at universities where the number of Japanese study abroad students were less in number. He saw this small population of Japanese students as his opportunity to avoid L1 contact and improve his English more naturally. That was the basis of his decision for the study abroad location. The wish to distance oneself from other Japanese student was also expressed by RA3 in his decision for a destination. He stated that:

"I hoped that there's not gonna be so many Japanese students there."

On the other hand, RA2 chose her study abroad location on the criteria that it was a place that was completely different to languages she had learned before. Her first inspiration, she claimed, was after seeing a video on Facebook. It showed comparisons of an English word (her example was ambulance) and in the video European language equivalents of the word were given with German last, sounding very different from other languages. Thus, she liked the uniqueness of the language and further thought that some European languages sounded cool. She said:

"German is quite different I guess. Really cool!"

All the RAs initially had different reason for wanting to study abroad beyond language development.

\subsection{Experience of Study Abroad}

The next logical topic to address after reasons for studying abroad is the experience that the three RAs had during their time abroad. Out of the three RAs, only RA3 had had previous experience in shorter study abroad courses. Indeed, he attended an international school at a very young age. All of these factors could have contributed to his adjustment into the study abroad setting. He also talked about feeling good while on a short program in Australia some years back. He claimed he had been trying to chase this same feeling ever since. He describes this good feeling as being in control of actions he wanted to do and not being put under pressure. RA3 also reinforced his idea that Japan is distinct from other places. He stated:

'Besides, during this year I experienced lots of things. In Japan, culture, system, and environments are totally different compared to other countries.'

This statement underlies a popular belief that Japan is very distinct from other cultures, and that most experiences had outside Japan will automatically be different from experiences had in Japan.

The three RAs also suffered from stressful situations while studying abroad. They all lived with people who were predominantly from various cultures in their dormitories. For RA3, being surrounded mostly by Dutch speakers 
of English, they would start speaking Dutch without realizing he was there. He did try to study Dutch, but he could only pick up a few words of what friends were talking about. He felt he was being intrusive by continually trying to ask what his friends were talking about when they spoke Dutch. His strategy for dealing with this situation was to speak to people individually so that they would:

"notice me more."

As more people noticed him, those friends agreed that Dutch language shouldn't be spoken in front of him. Lastly, RA3 also described a bad experience in a supermarket because he could not accomplish basic communication with the worker to explain what he wanted to buy. He said this really affected him and he felt a mixture of anger and embarrassment, which he would put to use to make more of an effort to learn the basics of the local language. These experiences would allow RA3 to become more aware of the plight of other study abroad students upon returning to Japan. He could understand study abroad students' viewpoint from his own experience.

While RA3 used one particular strategy to overcome communication problems, RA2 had a problem of sharing a flat with a student who had little interest in speaking the L2 German. RA2's roommate only spoke English to her. Although it was RA2's wish to converse in L2 German, she developed a strategy of opportunity. When speaking with her roommate, she made it her goal to speak in and develop her English communication skills. RA2 claimed she changed her own goals to accommodate this unexpected situation. In other words, she "saw it as a plus point" that she could improve her English when speaking to her roommate. A sense of adaptability is essential for study abroad.

\subsection{Developing Language Skills Whilst Abroad}

This next section deals with how the RAs went about developing their skills, mostly communication, during their time abroad. Two things become clear, the first being that personality plays a part in developing skills. All RAs could be described as quite outgoing in nature. Being gregarious enabled them to seek out and find opportunities for communication that other learners might not have put themselves in. Along with this outgoing nature, the second point is that they all claimed to have exerted an effort to force themselves to not speak Japanese, even with other Japanese students around. This often meant purposefully avoiding other Japanese study abroad students who were at their campuses.

The RAs also sought help and followed the lead of other more competent students. RA1 told me he had a friend from Qatar who spoke excellent English. In order to improve his own speaking skills, RA1 made a conscious effort to spend more time with that friend because he thought that by being with this more competent learner his own English would improve. It was not anything that the friend taught him directly, but RA1 said:

'I was stealing tips of speaking from him. If I heard phrases many times and I tried to use by myself many times'.

Skills development also came though reflection. RA2's first presentation in class did not go as well as she had expected. After that she claimed that she made a point of copying Germans to see how they were doing their presentations. The German students she watched seemed not to be presenting, she claimed, but actually 'teaching'. This included rearranging the classroom before the presentation to facilitate discussion. She also observed that during the presentations, and classes in general, other German students often gave their opinions. She said this forced her to make a change and imitate these actions and stated:

'I have to say opinion, I have to join more actively.'

By following how others were doing their presentations, by the third or fourth presentation she stated that she did not feel nervous anymore. When asked if she had felt that she had lead that group, she said yes, but with all other members. She further declared that organizing beforehand had really helped her to improve her presentation skills. Being able to read the situations in the environment around the students when they were abroad really helped them to adjust better to the L2 setting.

\subsection{Choosing to be an RA}

The position of RA was advertised while the current RAs were still studying abroad. The timing of this offer may have helped to motivate them to apply, as one of the biggest worries might be what will one do upon returning to Japan. The RAs in this study had different reasons for wanting to become RAs. RA2 wanted to use the opportunity to keep up her language skill. She had used what she referred as "tandem learning" often while abroad. Tandem learning is described as a process of mutual language exchange and she saw that learning was a process of "give and take." While abroad she had found situations where she learned German from some of her 
classmates, and taught Japanese in return. She would also use these sessions to exchange information and deepen interest in each other's cultures. Luckily, she had heard that Germans would be coming to Kanto University as study abroad students, so she was again keen to use the opportunity to share learning experiences.

Another motivation for wanting to become an RA was to provide support to study abroad students. Owing to the fact that RA3 had gone through initial problems during his study experiences, he thought other students should have an easier time. He wanted to provide assistance to those international students arriving to study generally and, more specifically, at Kanto University. He was sure language would be one of the main problems for international students.

In universities overseas the RA position is quite common and some of the RAs saw that this position was useful for them. RA3, in particular, consulted the RAs in his dormitory after not being able to study because of noisy roommates. The RA helped him to get over that problem by not only speaking to roommates, but continually asking RA3 how he was or how the situation was developing afterwards. He thought the RA was very helpful and supportive of him. He added that the RA tried to keep harmony within the dormitory and make it a comfortable living environment. This seems to have been influential in making RA3's mind up to apply for the RA job. He said:

'I would like to make a comfortable dorm and unforgettable memories for international students.'

Lastly, RA1 chose to apply for the RA position because he was influenced in a different way by RAs abroad. In the US, he saw an RA doing his / her job, and it looked fun. This helped him to decide to put himself in a position to entertain students who would be in unknown place. He emphasized that Japan would be totally different from visiting students' normal lives in their home countries, and it was important to entertain them to take their minds away from possible sources of adjustment stress.

\subsection{RAs Back in Japan}

This section has been added to show what happened abroad and how upon return to Japan the RAs view of themselves changed. First, while abroad, RA3 felt that he really wanted to stay in Holland, claiming that he was afraid to come back because his Japanese friends would not be as interested in improving their English as he was. Speaking upon his return, he said he does not see himself as a typical Japanese person anymore. He said:

'In Europe people think what they want to do, become motivated and happy, but in Japan people make a decision and others make their decision like that.'

He felt particular grievances such as a feeling that his Japanese friends don't tell the truth about what they really want to do. In an example of the above behavior, the topic of job-hunting arose. RA3 had been doing job-hunting activity at the time he relayed the story to the author. His friends were all asking him about what he was doing to find a job upon graduation to which he replied casually that he would 'get around to it'. His friends seemed shocked and pushed him to know why he would not engage in job-hunting more seriously and why he hadn't done so already, as was expected of Japanese students in their final year of university. In response to this, RA3 said he thinks Japanese have no other choice than to go through the rigors of job-hunting activities. He claimed he does have more choice. He went on to say he thinks that Japan is just a stepping stone before he goes onto to do something different in another country.

It appeared that like RA3, RA2 was also going through some conflicting thoughts about being back in Japan. Before she left for Germany she was not aware of her national characteristics as a Japanese person. It was only when it was pointed out to her by a lecturer before she left Japan that she recognized that. The point was that Japanese students tended to congregate together and only stay in their peer group even abroad. While she was in Germany she made a special effort to not be like that. This manifested itself in her avoiding meeting Japanese students while she was in Germany. They would be in the cafeteria, but she would try to ignore those people, instead choosing to associate with other foreign students. Now she is back in Japan, she is even more aware of these differences and feels strange when she encounters them. She proffered two examples. In the first, she invited a friend to drop by her house on the way to come to university. She said her friend continually asked if that was acceptable to do because the friend did not want to be intruding. RA2 thought it was strange and said:

'if it was not OK, she would have to ask in the first place.'

In the second example, her grandmother asked her to stop by her house, but the grandmother explained that she had not prepared any special food or drink for her. Even though it is customary to prepare something for guests, even family, RA2 felt it was strange for her grandmother to go to such lengths. It is clear in these instances that some qualitative change has taken place with the RAs which forces them to question some of their long-held beliefs about their own culture. 


\subsection{Doing the RA Job}

Once in the job, the RAs came to many different realizations. As enjoyable as the RAs express that the job is, difficulty was encountered regarding relationships between themselves and the international study abroad students. They all said that they realized the job entails being more than just acting as a conversation partner, but they expressed a tension between their job, wanting to help and actually being a friend to the visiting study abroad students. RA1 said that if he becomes more familiar with study abroad students it's difficult to organize the dormitory system. He noted:

"I want to not feel related to students."

This is especially difficult when there is a problem with untidiness in the dormitory that must be checked by the RAs. They all expressed difficulty in telling their friends to tidy up or obey rules more.

This relationship also plays out in the choice of language between RAs and study abroad students. Some study abroad students ask RA1 to speak Japanese with them. He responds in Japanese, if they speak Japanese to him first. He does not normally try to speak Japanese with them first. He claims that he feels the study abroad students might be 'ashamed' of their level of Japanese. On the same topic, RA2 agrees. The RAs try to establish a one-to-one relationship with each study abroad student, and they will speak Japanese individually with specific students who have high proficiency in L2 Japanese. This is especially true with visiting Chinese and Korean students who may not understand English. When there is an important message to give to study abroad students, such as details of an event, RAs use a Facebook group page, but post in both English and Japanese. RA1 sums up his feelings on the relationship by saying that RAs have to think of the other person, rather than their own goals.

In approaching which language to use with study abroad students, RA1 claimed before he studied abroad he was jealous of foreign students in Kanto University who spoke in English to a high proficiency. This was because he wanted to speak English like they did. However, after coming back to Japan, he started wondering why some of the international students in Kanto University choose not to speak in Japanese even though they study abroad to learn Japanese in Japan.

Looking at their own experiences while studying abroad, RA2 said she was strict on herself in Germany, so the author asked her why she speaks to students sometimes in Japanese and sometimes in English. She replied that she tries to gauge the motivation of the students and act accordingly. However, when I pointed out to her that she was very motivated and only wanted to speak the L2 language abroad, she said that she would like to really help students visiting Kanto University. She did think she should push visiting students to speak more Japanese and she was somewhat surprised that some students only go to the ECZ (a room where home and study abroad students can meet that prohibits the speaking of Japanese) and don't speak so much Japanese. She was also surprised at students who shun other study abroad students and try to learn Japanese by themselves, similar to how the RAs were in their study abroad location. RA2 said that she thought that some students could make more of an effort to get on with others in the dormitory, instead of ignoring them.

It also falls to the RAs to offer emotional support. RA3 talked about one international student who he thought looked lonely. He realized it could be that student's choice, but one day when RA3 was having lunch in the university cafeteria with other visiting students, he could see the student sitting in another area by himself. He said:

$$
\text { "It's kind of sad." }
$$

RA3 invited him to eat over with them at the table. At first the student would not engage with others, but others at the table started speaking to him and in the end he became involved and even appeared to enjoy the conversation.

Aside from emotionally supporting others in Japan, after arriving in the US, RA1 realized how beautiful Japan was, but also that he knew very little of anything of Japanese culture. He claimed:

"Even though, my friends always asked me about the politics and culture, I could only respond with short answers"

Partly because of this embarrassment, RA1 also believes that the role of RAs is to introduce visitors to Japan to Japanese culture. All RAs want the visiting students to take an interest in Japanese things. One way the RAs believed this could be achieved was through events. RA3 wished there had been more events during his stay abroad, especially in the first week. Not only could such events at Kanto University help to break the ice between home and visiting students, but also offer learning opportunities for each other's cultures. The RAs 
expressed regret that the theme of the parties in the international dormitory thus far had been more international in flavor, and less concentrated around Japanese themes. They all expressed a wish and need to make future parties and events related more to Japanese culture to peak international students' interest in the culture.

\section{Discussion}

Even though the above data constitutes around two and a half months of collection, a number of patterns emerge. In investigating the motivations for study abroad, a useful paradigm to use is the concept of possible selves (Markus \& Nurius, 1986). This theory (updated by Dörnyei, 2009) describes the ideal L2 self and the self one is afraid of becoming. These perceptions of oneself are more than just goals and involve vivid images that revolve around, for the male RA participants, avoidance of being left in a location where other Japanese language learners are, which could be perceived as detrimental to the RA's language learning. For the female RA participant, the ideal self is an image of looking 'cool' communicating in a second language that differentiates her from other Japanese learners. MacIntyre, MacKinnon, and Clément (2009) state that these possible selves, clearly linked to emotion, offer a clear path that can influence action towards fulfilling or avoiding that image.

The participants who saw contact with other Japanese students as impacting negatively on their perceived future self were not advised to avoid other Japanese learners, but believed that their presence could affect their own ability. Research has shown that some Japanese tend to keep up their associations with other Japanese outside the class, which negatively impacts on their chances for finding opportunities to communicate in the L2 (Robson, 2011; Tanaka, 2007). This is partly due to the collective nature of Japanese society.

The feeling of distance from Japanese people and culture can still be observed upon return to Japan. Researchers have claimed that the sojourner experience can change identities (Norton, 2014). Identities are based on knowledge and beliefs. For RA2, she did not now about the collective nature of Japanese; it was only when her tutor pointed this out to her. She was able to evaluation and assimilate this information during her study abroad. During study experiences the RAs would have interacted with people from different cultures, which has also been found to lead to identity change for sojourners (Sampasivam \& Clément, 2014). These salient differences would have also been confirmed through constant interaction with visiting students from Europe and America in their capacities as RAs.

Along with the changing identities of individual students, researchers into returnees also claim that difficulties are encountered into being accepted back in Japanese culture. Kidder (1992) states that some Japanese nationals are no longer considered "real Japanese" because there is a clear distinction between the homogeneous nature of Japan and the Japanese attitude of being unique that places people from other cultures on the outside. Interpersonal styles in Japan dictate that directness in conversation is avoided (Markus \& Kitayama, 1991). Both RA2 and RA3 detail instances where they have felt surprise by the reaction of their Japanese friends through discussion about things that have happened to them upon returning to Japan.

Whereas literature surrounding negative experiences of returnees exists (Enloe \& Lewin, 1987), other researchers point towards how the sojourner adapts back in their home culture. Sussman (2000) outlines a number of variables which can effect repatriation into the home environment. In her study, Sussman found that factors like the in ability to adapt and low self-esteem will negatively affect the identity upon return to the home country. Although RAs found inconsistencies between their home and host cultures, in their job of RAs, they were able to keep a professional distance between themselves and the visiting students, indicating good adaptability back into the culture. As for self-esteem, none of the RAs were suffering from low perceptions of themselves. Indeed, they were very confident about the future and where they wanted to be in the future, mostly outside of Japan. These outcomes contribute to the RAs having what Sussman called additive (positive experiences), being both multicultural and adapting to their life back in Japan, however, temporary.

\section{Conclusion}

This short paper addressed the perceptions and experiences of RAs from being first motivated to study abroad, through the study abroad experience. From there, this study looked at reasons for wanting to become an RA, and, lastly, addressed the issues that arose from doing the job of RA. It is clear that the paths that they took before becoming RAs helped to shape them and mold them into competent people to do the jobs of RAs. Among the issues, the ability to adapt to environments with a variety of people from different backgrounds and nationalities is essential in doing the job of RA. Along with this skill of adaption, a greater understanding of what it means to be Japanese is needed to both inform and advise visiting students about certain cultural inconsistencies as well as to maintain their own concept of self upon returning to Japan.

Where possible, it is important that universities offer more RA positions to help students adjust back into 
Japanese society. Universities also need to give consideration to the kind of applicant that becomes an RA. RAs need to exhibit a fair degree of cultural sensitivity. At present, students wishing to become an RA must complete an application form at Kanto University expressing their intentions to do the job. It is possible that further screening is needed through the use of an essay, which could require students to express their perceptions of the kind of issues that have been written about in this paper. As well as the application process, training for readjustment, addressing different identities and support should be given to RA workers who are on the job to help them facilitate, not only the job, but also their return to a potentially different culture; a point expressed by other researchers into returning students to Japan (Jones, 1997; Kanno, 2003).

Future research should follow the perceptions of continuing cohorts of RAs. Further, for a more holistic perspective more stakeholders should be involved in the research process. That includes management of the university and the visiting students themselves. The RA is the lifeline between the university and its guests. Care is needed in selecting, motivating and assisting the role of the RA.

\section{References}

Aamodt, M. G., Keller, R. J., Crawford, K. J., \& Kimbrough, W. W. (1981). A Critical-Incident Job Analysis of the University Housing Resident Assistant Position. Psychological Reports, 49, 983-986. http://dx.doi.org/10.2466/pr0.1981.49.3.983

Bierman, S. E., \& Carpenter, D. S. (1994). An Analysis of Resident Assistant Work Motivation. Journal of College Student Development, 35(6), 467-474.

Blimling, G. (1998). The resident assistant (5th ed.). Dubuque, IA: Kendall/Hunt.

Bowman, R., \& Bowman, V. (1995). Academic courses to train resident assistants. Journal of College Student Development, 36(1), 39-46.

D’Augelli, A. R. (1989). Homophobia in a university community: Views of prospective resident assistants. Journal of College Student Development, 30, 546-553.

Denzine, G. M., \& Anderson, C. M. (1999). I can do it: Resident assistants' sense of self-efficacy. Journal of College Student Development, 40(3), 247-255.

Dörnyei, Z. (2009). The L2 motivational self system. In Z. Dörnyei, \& E. Ushioda (Eds.), Motivation, language identity and the L2 self (pp. 43-65). Bristol, UK: Multilingual Matters.

Enloe, W., \& Lewin, P. (1987). Issues of integration abroad and readjustment to Japan of Japanese returnees. $\begin{array}{lllll}\text { International Journal of Intercultural Relations, } & 11(3), & \text { 223-248. }\end{array}$ http://dx.doi.org/10.1016/0147-1767(87)90002-2

Evans, N. J., \& Broido, E. M. (1999). Coming out in college residence halls: Negotiation, meaning making, challenges, supports. Journal of College Student Development, 40, 658-668. Retrieved 1st April, 2016, from http://multipleidentitieslgbtq.wiki.westga.edu/file/view/EvansBroido1999.pdf/274986922/EvansBroido199 9.pdf

Freed, B. F. (1998). An overview of issues and research in language learning in a study abroad setting. Frontiers: The Interdisciplinary Journal of Study Abroad, 4, 31-60.

Harmon, W. R. F. (2011). Behind two doors: the lived Experience of resident assistants in Transition at a midwestern University (Doctoral dissertation, University of Nebraska, Lincoln, Nebraska).

Jones, H. (1997). Returning home after study abroad. The Language Teacher, 21(11). Retrieved 1st May, 2016, from http://jalt-publications.org/ttt/articles/2229-returning-home-after-studying-abroad

Kanno, Y. (2003). Negotiating bilingual and bicultural identities: Japanese returnees betwixt two worlds. Mahwah, N.J.: Lawrence Erlbaum Associates.

Kidder, L. H. (1992) Requirements for Being "Japanese": Stories of returnees. International Journal of Intercultural Relations, 16(4), 383-393. http://dx.doi.org/10.1016/0147-1767(92)90029-T

M.E.X.T. (2015). The number of Japanese nationals studying overseas and the annual survey of international students in Japan. Tokyo: Author. Retrieved January 30, 2016, from http://www.mext.go.jp/english/topics/1357495.htm

MacIntyre, P. D., Mackinnon, S. P., \& Clément, R. (2009). The baby, the bathwater, and the future of language learning motivation research. In Z. Dörnyei, \& E. Ushioda (Eds.), Motivation, language identity and the L2 self (pp. 9-42). Bristol, UK: Multilingual Matters. 
Markus, H. R., \& Kitayama, S. (1991). Culture and the self: Implications for cognition, emotion, and motivation. Psychological Review, 98, 224-253. http://dx.doi.org/10.1037/0033-295X.98.2.224

Markus, H. R., \& Nurius, P. (1986). Possible selves. American Psychologist, 41, 954-969. http://dx.doi.ord/10.1037/0003-066x.41.9.954

Miles, M. B., \& Huberman, A. M. (1994). Qualitative data analysis: An expanded sourcebook (2nd ed.). Thousand Oaks, C.A.: Sage.

Norton, B. (2014). Identity and poststructuralist theory in SLA. In S. Mercer, \& M. Williams (Eds.), Multiple Perspectives on the Self in SLA (pp. 59-74). Bristol/Buffalo/Toronto: Multilingual Matters.

Robson, G. (2011). 17. Students' experiences of a short homestay in England-The case of Regional Studies students. Journal of Tourism Studies, 10, 127-48.

Roussel, T., \& Elleven, R. K. (2009). Improving resident assistants: Female and male chief housing officers in Christian colleges and universities. Christian Higher Education, 8(5), 393-404. http://dx.doi.org/10.1080/15363750902973519

Sampasivam, S., \& Clément, R. (2014). The dynamics of second language confidence: Contact and interaction. In S. Mercer, \& M. Williams (Eds.), Multiple Perspectives on the Self in SLA (pp. 23-40). Bristol/Buffalo/Toronto: Multilingual Matters.

Shelton, J. L., \& Mathis, H. V. (1976). Assertiveness as a predictor of resident assistant effectiveness. Journal of College Student Personnel, 17(5), 368-370.

Spradley, J. P. (1979). The ethnographic interview. Fort Worth, Texas: Harcourt Brace Janovich.

Sussman, N. M. (2000). The dynamic nature of cultural identity throughout cultural transitions: Why home is not so sweet. Personality and Social Psychology Review, 4(4), 355-373. http://dx.doi.org/10.1207/S15327957PSPR0404_5

Tanaka, K. (2007). Japanese students' contacts with English outside the classroom during study abroad. Applied Linguistics, 13(1), 36-54.

\section{Copyrights}

Copyright for this article is retained by the author(s), with first publication rights granted to the journal.

This is an open-access article distributed under the terms and conditions of the Creative Commons Attribution license (http://creativecommons.org/licenses/by/4.0/). 